\title{
Femur çivilemelerindeki femur başı vidalarını ideal pozisyonda yollamaya yardımcı aparat sistemi
}

\author{
An apparatus system that help to place femoral head screws \\ in the ideal position in femoral nailing
}

\author{
Oğuz Şükrü Poyanlı \\ İstanbul Medeniyet Üniversitesi Tıp Fakültesi, Ortopedi ve Travmatoloji Ana Bilim Dalı, İstanbul \\ Göztepe Prof. Dr. Süleyman Yalçın Şehir Hastanesi, Ortopedi ve Travmatoloji Kliniği, İstanbul
}

Bu buluş; proksimal femur kırık çivilemelerinde femur baş vidası/vidalarını hastaya zarar vermeden ideal pozisyonda yollamaya yardımcı olan, farklı malzemelerden üretilebilen bir aparat sistemi ile ilgilidir. Konuyla ilgili patent dosyası paylaşılmıştır. Femur başına gönderilen vidaların tam ortada olmasının, kırığın daha sonra olası redüksiyon kaybını engellediği, ayrıca vidaların femur başını keserek dışarı çıkmaları yani cut-out ihtimalini azalttığı gösterilmiştir.

Anahtar sözcülkler: patent; proksimal femur kırıkları; kanal içi çivileme; ideal pozisyonda vida yollama; yardımcı aparat sistemi

\section{T. C. Türk Patent Enstitüsü'ne Patent Belgesi için Başvuru Bilgileri[ ${ }^{[1]}$}

Başvuru bilgileri Tablo 1'de gösterilmiştir. ${ }^{[1]}$

Tablo 1. Başvuru bilgileri[ ${ }^{1]}$

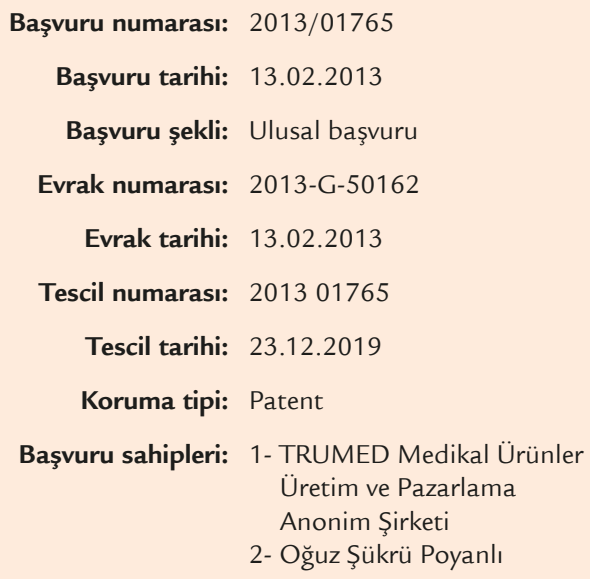

Buluş sahipleri: Oğuz Şükrü Poyanlı
This invention relates to an apparatus system that can be produced from different materials that helps to screw femoral head in the ideal position harmlessly in proximal femoral fracture nailing. The patent file on the subject has been shared. It has been shown that screwing femoral head centrally prevents the possible loss of reduction, and reduces the cut-out possibility.

Key words: patent; proximal femur fractures; intramedullary nailing; screw in the ideal position; supporting apparatus system

\section{PATENT BELGESI - No: TR $201301765^{[1]}$}

\section{Teknolojik Alan ${ }^{[1]}$}

"Bu buluş; proksimal femur kırık çivilemelerinde femur baş vidası/vidaların hastaya zarar vermeden ideal pozisyonda yollamaya yardımcı olan, farklı malzemelerden üretilebilen bir aparat sistemi olan 'Femur çivilemelerindeki femur baş vidalarını ideal pozisyonda yollamaya yardımo aparat sistemi' ile ilgilidir. ${ }^{[1] "}$

\section{Tekniğin Bilinen Durumu[1]}

“Günümüzde proksimal femur kırık çivilemelerinde femur baş vidası/vidalarını femur başına göndermeye yardımcı olarak kullanılan tüm kılavuz sistemlerinde, önce kılavuz içerisinden femur başına yani hastanın kemiğine bir Kirschner teli gönderilir. Ya da femur boynunun anatomisine paralel bir Kirschner teli gönderilerek skopide bakılır. Bu yöntemlerde femur başını tam ortalamak her zaman mümkün olmamaktadır. Kullanılan kılavuz sistemleri ile, Kirschner telini uygun pozisyon elde edilinceye kadar femur başına tekrar tekrar ideal pozisyon elde edilene kadar göndermek gerekmektedir."

- İletişim adresi: Prof. Dr. Oğuz Şükrü Poyanlı, İstanbul Medeniyet Üniversitesi Tıp Fakültesi, Ortopedi ve Travmatoloji Ana Bilim Dalı, Kadıköy, İstanbul Tel: 0532 - 3170750 e-posta: opoyanli@gmail.com ORCID iD: 0000-0002-4126-0306

- Geliș tarihi: 30 Kasım 2020 Kabul tarihi: 12 Aralık 2020 


\section{Şekillerdeki (Parçaların) Referans Numaralarının Açıklanması ${ }^{[1]}$}

"1- Anatomik tasarımlı proksimal femur çivisi (să̆ ve sol femur için farklı anatomide tasarlanmış) ${ }^{[2]}$

2- C kılavuzu

3- Üst kılavuz

4- Üst kılavuzun C kılavuzuna oturmasını sağlayan pimleri

5- Üst kılavuzun pimlerinin yuvaları

6- Üst kılavuzu C kılavuzuna sabitleyen vida

7- Üst kılavuzu C kılavuzuna sabitleyen vidanın yuvası

8- Hizalama çubuğunun üst kılavuzda yerleştiği delikler

9- Hizalama çubuğu

10- Femur başı vidaları

Bu buluşun anlaşılmasına yardımcı olacak şekiller Şekil 1 ve Şekil 2'de gösterilmiştir.

\section{Buluşun Açıklanması ${ }^{[1]}$}

Buluş, bir adet üst kılavuz (3), üst kılavuzun C kılavuzuna oturmasını sağlayan iki adet pimleri (4), üst kılavuzun pimlerinin yuvaları (5), üst kılavuzu C kılavuzuna sabitleyen bir adet vida (6), üst kılavuzu C kılavuzuna sabitleyen vidanın yuvası (7), hizalama çubuğunun üst kılavuzda yerleştiği iki adet delik (8) ve bir adet hizalama çubuğundan (9) oluşmaktadır. ${ }^{[1]}$

Femur başına gönderilen vidaların tam ortada olmasının, kırı̆̆ın daha sonra olası redüksiyon kaybını engellediği, vidaların femur başını keserek dışarı çıkmaları yani cut-out ihtimalini azalttığı gösterilmiştir ${ }^{[3]}$. Bu sebeple bütün proksimal femur kırıklarının çiviyle tedavisinde vidaların femur boynuna en ideal pozisyonda gönderilmeleri amaçlanır. Bu buluş, tek seferde, hastaya herhangi bir zarar vermeden femur başını ortalayacak şekilde vidaların gönderilmesine olanak sağlayan bir sistemdir.

Bu buluş kullanılırken önce proksimal femur çivisi (1), C kılavuzuna (2) takılır. Üst kılavuzun C kılavuzuna oturmasını sağlayan pimleri (4), üst kılavuza (3) monteli haldedir. Üst kılavuzun pimlerinin yuvaları (5) ise C kılavuzun (2) üzerindedir. Üst kılavuz (3), üst kılavuzun C kılavuzuna oturmasını sağlayan pimleriyle (4) Üst kılavuzun pimlerinin yuvalarına (5) oturtulur. Daha sonra üst kılavuzu C kılavuzuna sabitleyen vida (6), üst kılavuzu C kılavuzuna sabitleyen vidanın yuvasından (7) gönderilerek üst kılavuz (3) C kılavuzuna (2) vidalanarak sabitlenir (Şekil 1 ve 2). [1]

Femur başı vidalarının (10) femur başına gönderilirken hizalanmalarına yardımcı olarak hizalama çubuğu (9) kullanılır. Bunun için üst kılavuzda (3) bulunan hizalama çubuğunun üst kılavuzda yerleştiği delikler (8) içinden uygun olanından (săg veya sol femur olmasına göre değisşen) bir adet hizalama çubuğu (9) yerleştirilir. Hizalama çubuğu (9), hizalama çubuğunun üst kılavuzda yerleştiği deliklere (8) sabitlenmez, hareket eder haldedir (Şekil 1-4). [1]

$B u$ buluşta hastanın vücuduna herhangi bir işlem yapmadan, anatomik olan proksimal femur çivisinin (1) anteversiyonuna eşit paralellikte bir hizalama çubuğu (9) vücut dışından gönderilir (Şekil 5). Bu durumda, vücut dışından serbest olarak femur başına paralel yollanılan hizalama çubuğunun (9) anteversiyonu ile sistemin anteversiyonu lateral grafide paralel olduğu için, çivi (1) femurun içinde ise gönderilmiş hizalama çubuğu (9) da femur boynunun tam ortasında olur (Şekil 6a ve 6b). Böylece femur başı vidaları (10) direkt gönderilebilir. Bu da hem skopi süresini azaltır, hem de hastaya elle yani Kirschner teli göndermeyle yapılacak zararı önler. Günümüzde bu şekilde fonksiyonu olan, tanımlanmış bir kılavuz sistemi yoktur. ${ }^{[1]}$

Anatomik bir çivi kullanıldığında, ameliyat sırasında proksimal femur çivisi (1) femura yerleştirildiğinde, bu buluşta lateral grafide vücut dışındaki kılavuzun (2) anteriorunda femur başı rahatıkla görülebilir. Normal düz sistemlerde ise femur başını tam ortalamak her zaman mümkün olmamaktadır. Bu buluşta anatomik bir aparat sistemi kullanıldığı için, hizalama çubuğu (9) vücut dışından femur başına paralel olacak şekilde yerleştirildiğinde sistem anatomik olduğu için bu ikisi üst üste gelerek femur başı rahatıkla görülebilmektedir, C kılavuzunun (2) yeri hiç bozulmamaktadır. Hizalama çubuğunun (9) görülmesinde C kılavuzu (2) hiç engel olmamaktadır. Bu buluşta tekniğin bilinen durumundan farklı olarak sistem anatomik olduğu için hizalama çubuğu (9), C kılavuz sisteminin dışında görüntü verebilmektedir. ${ }^{[1]}$

Bu buluş, operasyonun uygulanmasını kolaylaştırması, operasyonun süresini kısaltması, skopi kullanımını azaltması, Kirschner telinin kılavuza yardımcı olarak femur başına tekrar tekrar gönderilmesini engelleyerek bu yolla oluşacak kemik ve yumuşak doku hasarlanmasını önlemesi, dolaylı olarak da enfeksiyon riskini azaltması, femur başı vidasının cut-out (kesme) riskini ortadan kaldırması, implantın cilt irritasyonunu en aza indirmesi ve ekstremitenin erken fonksiyonel kullanımına izin vermesi yönleriyle diğer cerrahi tedavi yöntemlerine üstünlük sağlar. ${ }^{[1,4] "}$

\section{İstemler ${ }^{[1]}$}

"1- Bu buluş "Femur çivilemelerindeki femur başı vidaları$n ı$ ideal pozisyonda yollamaya yardımcı aparat sistemi" olup, özelliği; bir adet üst kılavuz (3), iki adet üst kılavuzun C kılavuzuna oturmasını sağlayan pimleri (4), üst kılavuzun pimlerinin yuvaları (5), bir adet üst kılavuzu C kılavuzuna sabitleyen vida (6), üst kılavuzu C kılavuzuna sabitleyen vidanın yuvası (7), iki adet hizalama çubuğunun üst kılavuzda yerleştiği delik (8) ve bir adet hizalama çubuğundan (9) oluşmasıdır. ${ }^{[1]}$ 
2- İstem 1'de bahsedilen üst kılavuz (3) olup, özelliği; içerisine üst kılavuzun C kılavuzuna oturmasını sağlayan pimleri (4) monte edilmiş üst kılavuzun pimlerinin yuvalarına (5), içerisinden bir adet üst kılavuzu C kılavuzuna sabitleyen vida (6) geçen üst kılavuzu C kılavuzuna sabitleyen vidanın yuvasına (7) ve hizalama çubuğunun (9) içerisinden geçeceği iki adet Hizalama çubuğunun üst kılavuzda yerleştiği deliğe (8) sahip olmasıdır. ${ }^{[1] "}$

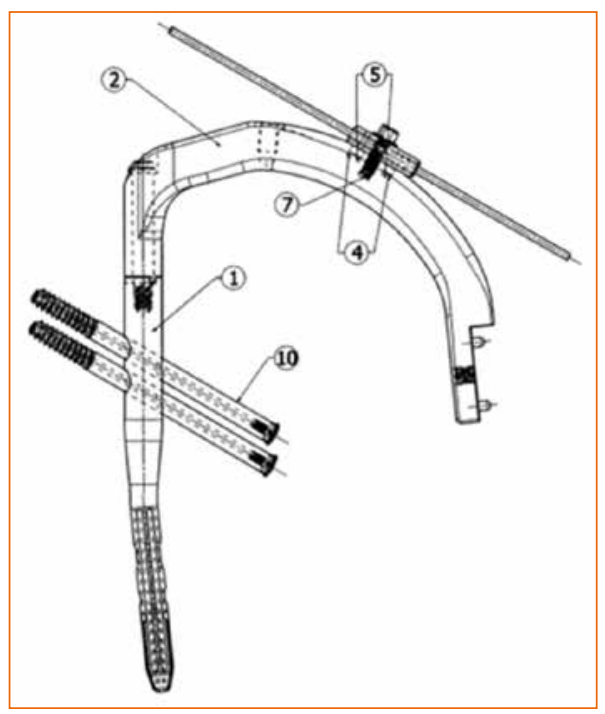

Şekil 1. Anatomik çivi ve çakma setine tespit edilmiş aparatın şematik yandan görünüşü. ${ }^{[1]}$

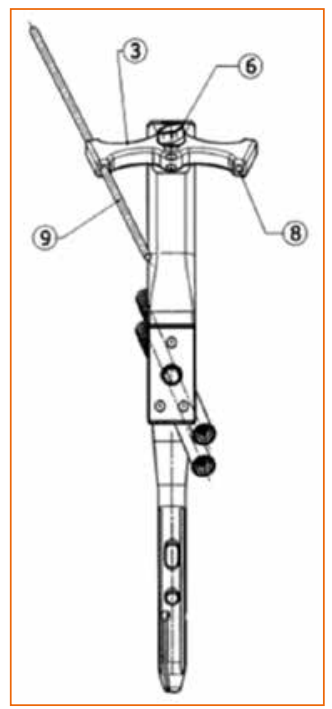

Şekil 2. Anatomik çivi ve çakma setine tespit edilmiş aparatın şematik iç önden görünüşü. ${ }^{[1]}$

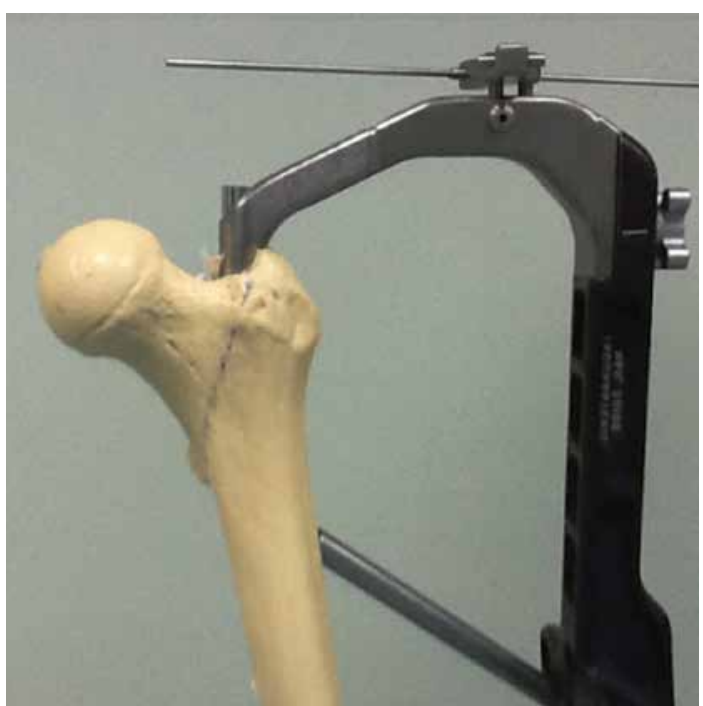

Şekil 3. Yapay kemik üzerine uygulanan çivi ve çakma setine tespitli aparat yandan görünüşü.

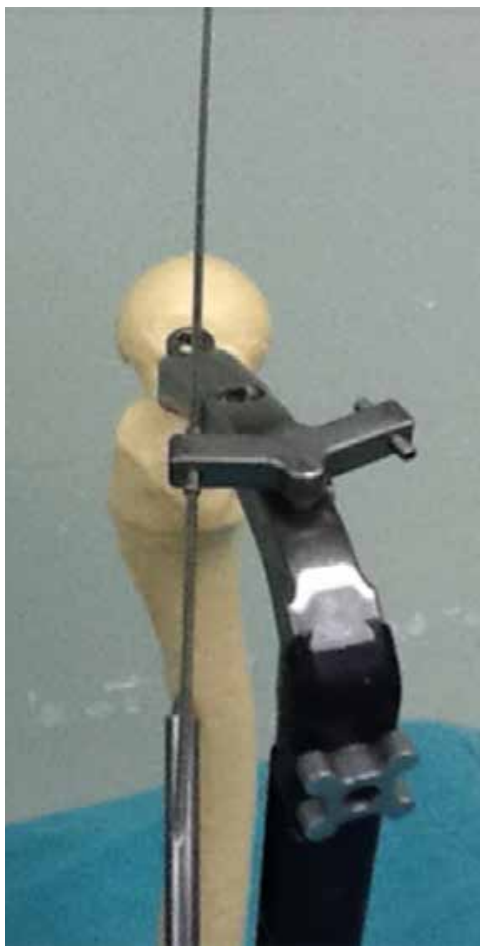

Şekil 4. Yapay kemik üzerine uygulanan çivi ve çakma setine tespitli aparat üst çaprazdan görünüşü.

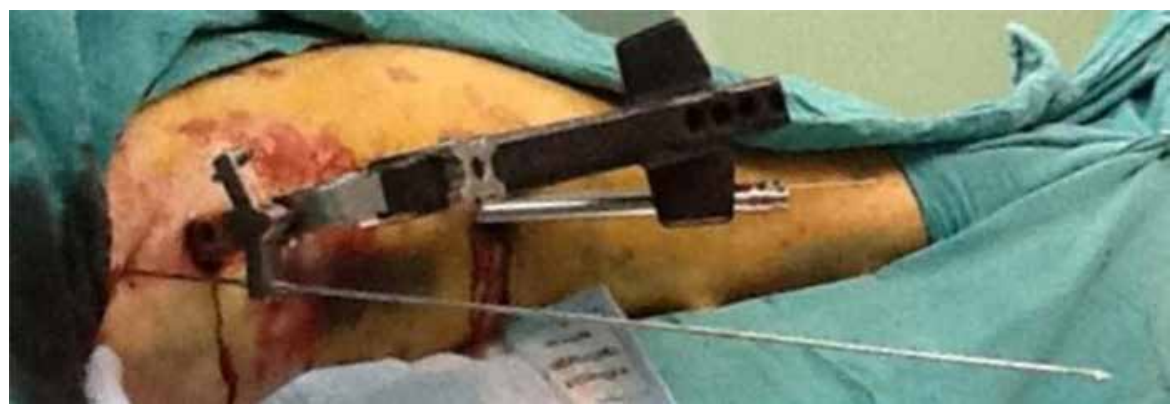

Şekil 5. Ameliyat sırasında hizalama çubuğunun aparatın içinden gönderilmesi.
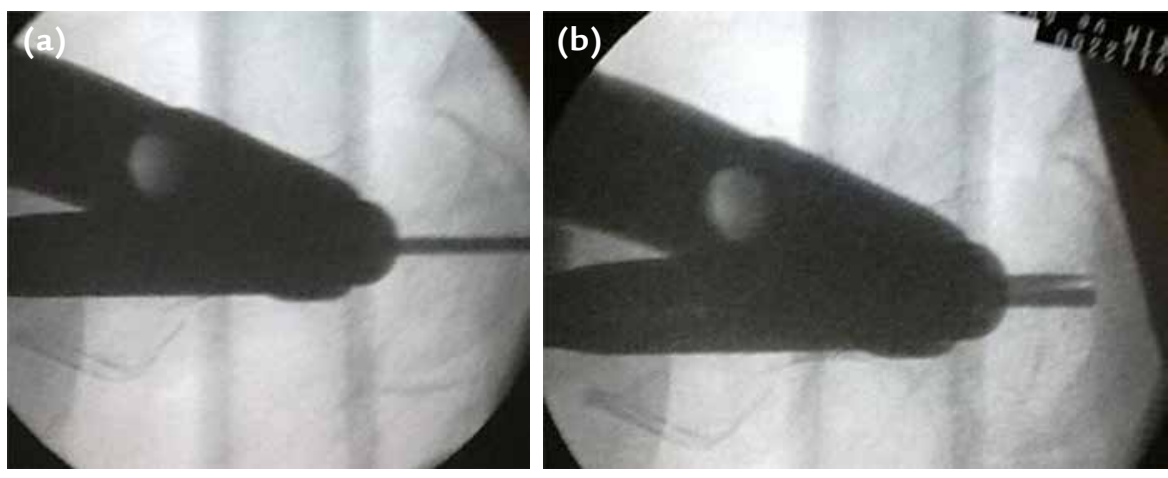

Şekil 6. a, b. Hizalama çubuğunun lateral skopi görüntüsünde femur başının anteversiyonu ile aynı ve tam ortada olduğu görülmektedir (a). Sistemin içinden femur başına yollanan vidaların kılavuzunun lateral skopi görüntüsünde femur başının tam ortasında olduğu görülmektedir (b). 


\section{YAZARIN KONUYLA ILGILI ÇALIŞMALARI}

Poyanlı O, Söylemez S, Özkut AT, Uygur E, Kemah B, Ünal OK. Precise placement of lag screws in operative treatment of trochanteric femoral fractures with a new guide system. Injury, vol. 46, no. 11, pp. 2190-2195, Nov. 2015.[4]

\section{KAYNAKLAR}

1. Femur çivilemelerindeki femur başı vidalarını ideal pozisyonda yollamaya yardımcı aparat sistemi. T.C. Türk Patent Enstitüsü. Patent Belgesi. No: 2013 01765. https://portal.turkpatent. gov.tr/anonim/arastirma/patent/detayli
2. İntramedüller olarak uygulanan trokanterik çivi. T.C. Türk Patent Enstitüsü. Faydalı Model Belgesi. No: 2011/05496. https://portal.turkpatent.gov.tr/anonim/arastirma/patent/ detayli

3. Baumgaertner MR, Curtin SL, Lindskog DM. Intramedullary versus extramedullary fixation for the treatment of intertrochanteric hip fractures. Clin Orthop Relat Res 1998;348:87-94. Crossref

4. Poyanlı O, Söylemez S, Özkut AT, Uygur E, Kemah B, Ünal OK. Precise placement of lag screws in operative treatment of trochanteric femoral fractures with a new guide system. Injury 2015;46:2190-5. Crossref 